\title{
Designing and Simulation of Surrounding Supporting Multicast Routing Protocol
}

\author{
Shaik Mahaboob Jani, Syed Umar, P.V.R.D Prasada Rao, Sridevi Gutta
}

Dept of CSE, K L University, Guntur, AP, India

\begin{tabular}{l}
\hline \hline Article Info \\
\hline Article history: \\
Received Sep 30, 2015 \\
Revised Dec 20, 2015 \\
Accepted Jan 9, 2016 \\
\hline
\end{tabular}

\section{Keyword:}

Network lifetime

Routing protocols

Wireless technology

\begin{abstract}
In the Wireless sensor networks having of multi-hop transmission in the Adhoc networks. These Adhoc networks having advantages of limited bandwidth and mobility which is more useful for the changing of and usage of various protocols, so that these Adhoc networks having energy conservation, simple to construct, robustness. In this paper we are proposing a new protocol called Surrounding supporting multicast routing protocol [SSMRP]. This protocol uses the mesh networks to enhance the resilience against change of node. This SSMRP utilizes the node locality which reduces the overhead of the route maintenance and it also reduces the route for good data transmissions. In this paper we clearly explains how the data will be delivered efficiently by reducing the overheads
\end{abstract}

Copyright () 2016 Institute of Advanced Engineering and Science. All rights reserved.

\section{Corresponding Author:}

Shaik Mahaboob Jani

Dept of CSE, K L University, Guntur, AP, India.

Email: shaik2signin@gmail.com

\section{INTRODUCTION}

In the Wireless sensor networks the Adhoc networks will play a major role in the collection of the mobile nodes with the support of fixed infrastructure which contains self-organised nodes and provides best communication protocols between the nodes in any environments. The Adhoc networks are more important in classrooms because these can share the information dynamically to all the nodes or computing devices. Each node in the Adhoc networks will acts as router which can establish the end to end communications. To say that particular network is Adhoc network then it has to satisfy the some unique characteristics like design should be simple, robustness, good memory capabilities, energy conservation when it is used in batteries. In the Adhoc network the topology is inherently volatile and routing algorithms and it should be robust against the topology whenever changes.

The routing protocols in the Adhoc networks are broadly categorized as three types: proactive protocols, active protocols and hybrid Protocols. The proactive routing protocols will continuously make immediate decisions on routing to transmit the data to the nodes. Some of protocols in which this implemented is DSDV [1], WRP [2], DBF [3]. Reactive protocols are sets the routes on basis of needs some of the protocols are RDMAR [4], AODV [5], ABR [6], DSR [7], TORA [8].

As based on the direction of the routing protocols are of two types one os unicast and other is multicast routing for the ad hoc networks. In this proposal we used the multicast routing protocol [9], [10]. These are again classified as tree based and mesh based protocols. In this we used the mesh based networks which is a new on demand multicast routing protocol called Surrouding Support Multicast Routing Protocol. While simulating these in the normal and periodic mesh maintainances towards the forwarding nodes and its neighbors to transmit the control messages so new selected nodes will be used in the route which uses the SSMR protocol, so we can maintain the better route efficiency for reducing the nodes. 


\section{BRIEF VIEW ABOUT THE SSMR PROTOCOL}

A soft state approach is used in the SSMR protocol to build the routes maintained with basic information like route discovery etc., and it robust and efficient Adhoc multicast routing. SSMR protocol performs the flooding technique to find the path from the source to destination occasionally. To the nodes which are connected as long lived will have to maintain the route path, so by this route efficacy will be maintained and the multicasting will be done, it is well known as the mesh structure or tree structure

\section{A. Creation of Multicast Mesh Network}

In this network the node of source will send the FLOOD_REQ to the nodes which is set as an upstream node. This request will be received by the intermediate nodes which will updates the bit fields then it sends the reply packet to the node that it receives the packets and these are called as forwarding nodes. If these nodes are of multi cars mesh network called mesh nodes which is shown in below Figure 1a shows the initial mode of the creation of the multicast network. Figure $1 \mathrm{~b}$ shows the final creation of the mesh multicast network.

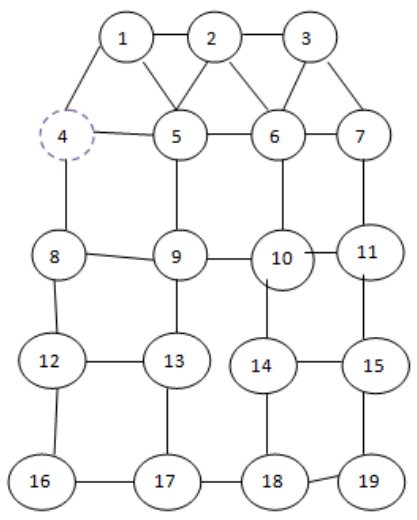

Figure 1a. Shows the initial mode of the creation of the multicast network
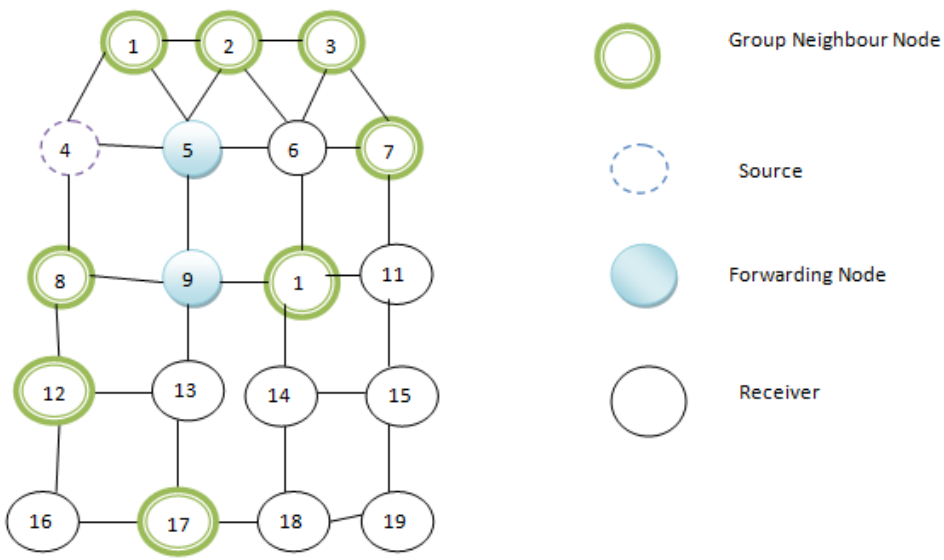

Figure 1b. Shows the final creation of the mesh multicast network

\section{B. Maintenance of the Multicast Mesh Network}

In this stage we use certain techniques to find the route is discovering of local route with sending a message CAL_REQ packet to the mesh nodes and the intermediate nodes will receive and send reply as LOCAL_REQ and the FLOOOD_REQ will also be transmit by the nodes. These are shown in the Figure 2 Maintenance of the multicast mesh link failure and recovery of local. If Annu route or path failure occurs then local route discovery ensures the control on overhead but it does not repair it link failure so with the network connectivity, the locally recoverable link failure occurs with less frequently than the link failures. The Discovery of Flooding route is used in the SSMR protocol to send the message FLOOD_REQ to create 
a mesh topology among the nodes, then the nodes joined in the topology reply as LOCAL_REQ packet. Another methodology is the Route efficiencyimprovement play a vital role in the route maintenance in the selected path with more number of forwarding nodes. This factor plays a major role in the route efficiency.
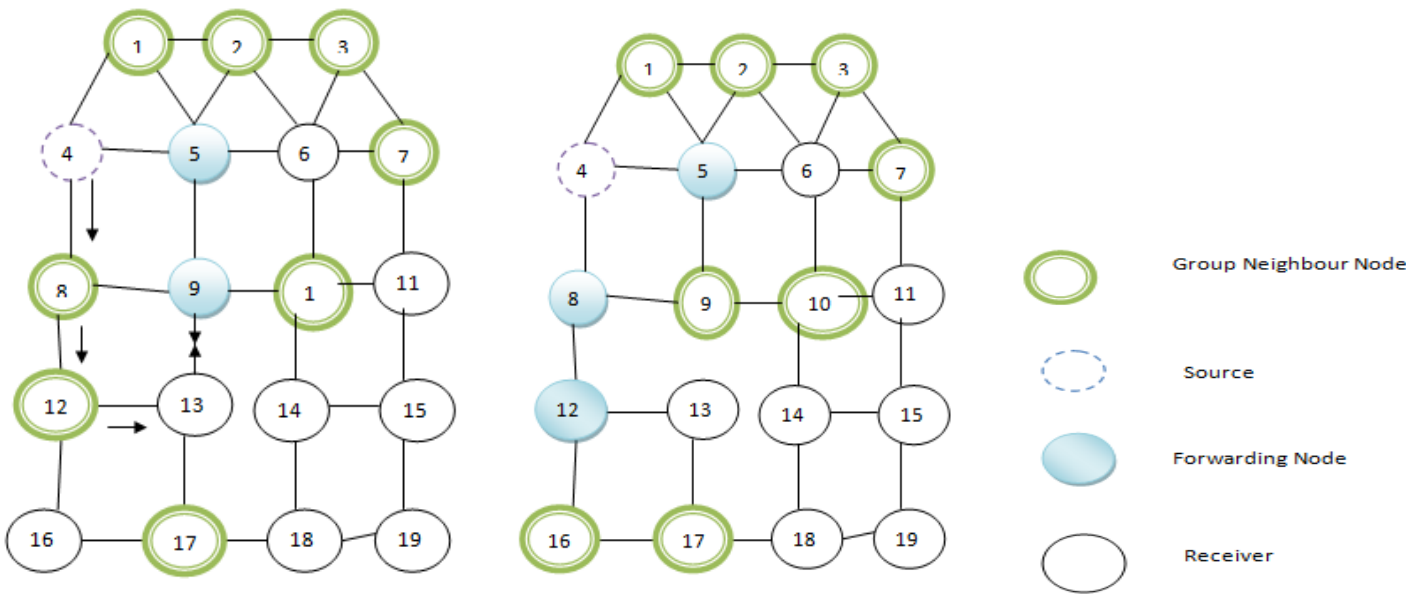

Figure 2. Maintenance of the multicast mesh link failure and recovery of local

\section{SSMR PROTOCOL ANALYSIS \& SIMULATION}

The Figure 3 shows the packet header of the SSMR protocol. While routing from source to destination a routing table will be maintained at each node which is shown in the Figure 4 . The routing table consists of columns like forwarding flag used for the forwarding nodes which will set the group neighbour flag when the node is in a group. In each and every node of the group of mesh topology network maintains the data cache and a cache to avoid the duplication of data which is shown in Figure 5. And the source node will have a source address of the group. After requesting stage of the nodes completions then the reply stage will initiates, after the path extablishment from source to destination and in the same way reverse path also established in the upstream field of the REQ_CACHE. Whenever the nodes fails then immediate will set the path and send the message REP to the upstream node means after the initiation of the path if any failure occurs then immediately alternate node will come into existence by relay mechanism. Before that the nodes has to understand that where is the group neighbour and how to become the member of the neighbour group if it is non mesh network they by using the Upstream field a route is discovered with a packet which contains the source address field of the packet. The Table 1 shows the behaviour of the route discovery packets.

\begin{tabular}{|c|c|c|c|c|c|c|}
\hline Type & $\begin{array}{c}\text { Sequence } \\
\text { number }\end{array}$ & $\begin{array}{c}\text { Group } \\
\text { address }\end{array}$ & $\begin{array}{c}\text { Source } \\
\text { address }\end{array}$ & upstream & FC & NC \\
\hline
\end{tabular}

Figure 3. SSMR packet header

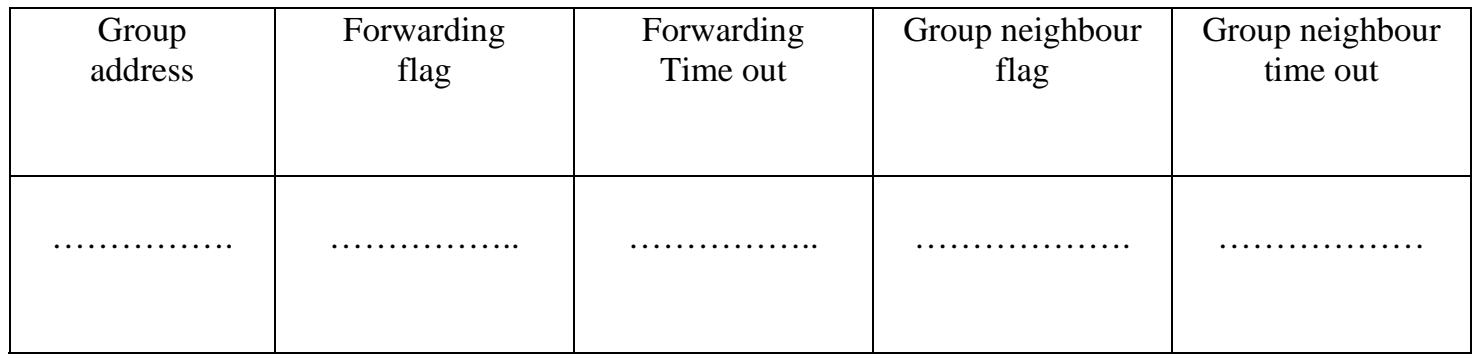

Figure 4. Routing table used at the nodes of SSMR 


\begin{tabular}{|l|c|c|}
\hline Source address & Group address & Sequence number \\
\hline$\ldots \ldots \ldots \ldots \ldots \ldots \ldots \ldots \ldots \ldots \ldots \ldots \ldots \ldots \ldots \ldots \ldots \ldots \ldots \ldots \ldots \ldots \ldots \ldots$ & \\
\hline
\end{tabular}

(a)

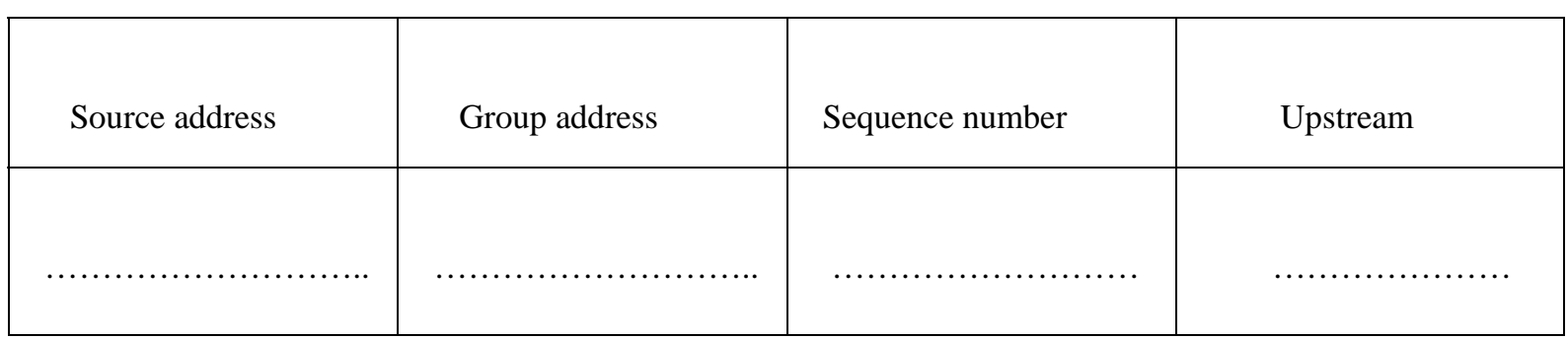

(b)

Figure 5. a) Data cache b) Req Cache used un SSMR

Table 1. Node behaviour when a node discovers the route

\begin{tabular}{llllcc}
\hline Route discovery & Source & Receiver & Forwading node & Group neighbor & Other node \\
\hline Flooding & Update source table & Send REP & & $*$ & $* *$ \\
& Relay & Relay & Relay & $\begin{array}{c}\text { Relay } \\
*\end{array}$ & Relay \\
Local & $\begin{array}{l}\text { Update source table } \\
\text { Relay }\end{array}$ & Send REP & & Relay & \\
& & Relay & Relay & &
\end{tabular}

**The node becomes a group neighbour if Source Address= Upstream.

\subsection{Simulation Analysis}

For simulation of this SSMR protocol we used ns2 simulator in which we use the some parameter like FLOOD_PERIOD used for the deliverers time ration and the control overhead of the SSMR protocol. In the fig 6 we can clearly observe analyse the packet delivery ratio increases when the FLOOD_PERIOD reduces from 100 to $20 \mathrm{~s}$ and the delivery ratio increases to $6 \%$ and we can also reduce the from $20 \mathrm{~s}$ to $2 \mathrm{~s}$ from the fig 6 we can also explains the transmission range is very shortest. So to study the impact factor of the preferring nodes which can establish a reverse route will be used a below function

$$
\text { Metric }=(1-\mathrm{a}) * \mathrm{FC}+\mathrm{a} * \mathrm{NC}, 0<=\mathrm{a} \& \mathrm{a}<=1
$$




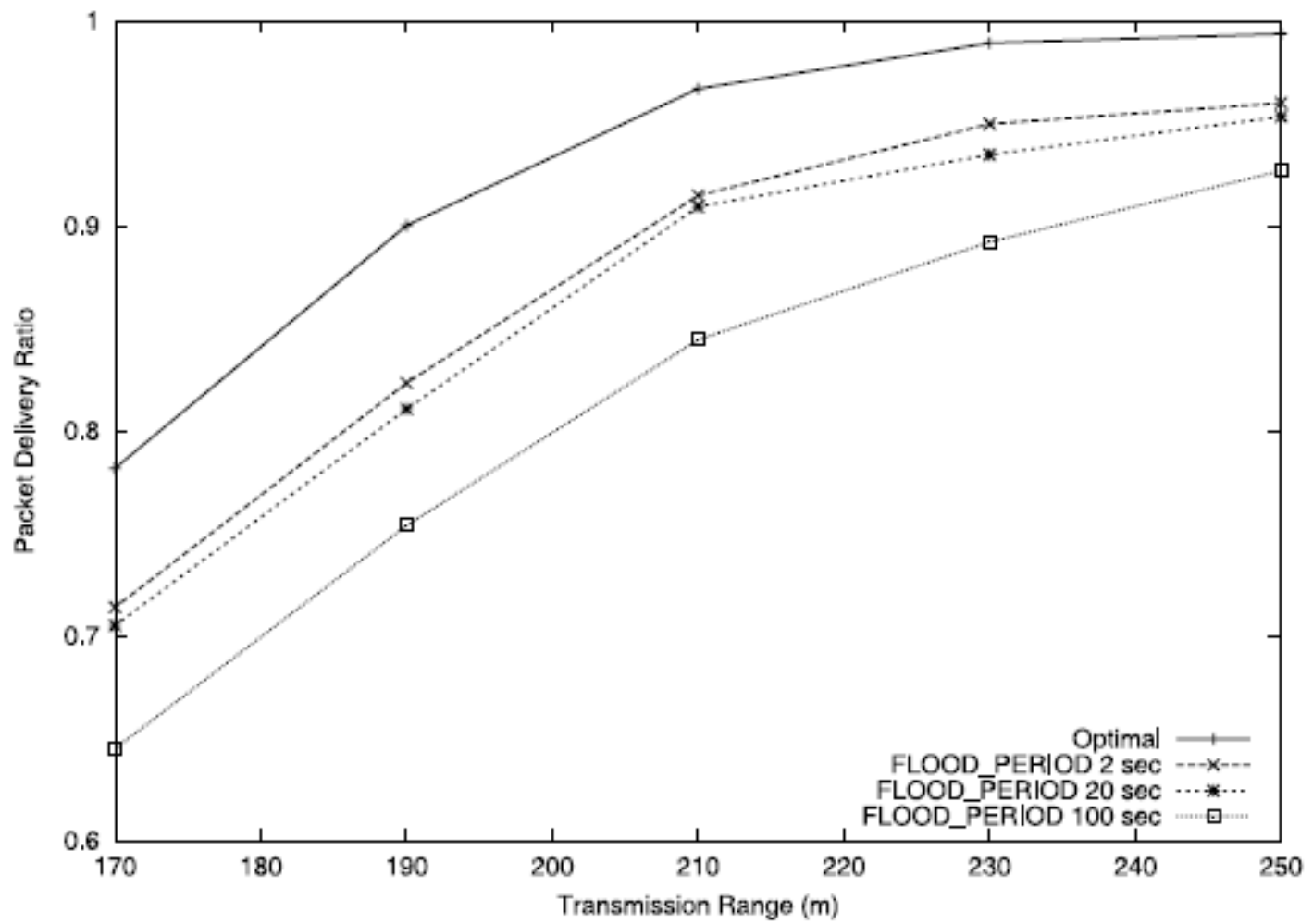

Figure 6. Ratio Data delivery with different FLOOD_PERIOD

By varying the value of 'a' from 0.4 to 0.5 and 0.6 then we can see the packet delivery ratio and group size in the below Figure 7 and we can clearly examines that the packet delivery will not show any impact on the group size. The ratio of data packets and the total data packets delivered is called the function of the group size. From this we can say that as the group size increases then the reduces more significantly which is shown in the Figure 8 and the reduction ration will be of $1 \%$

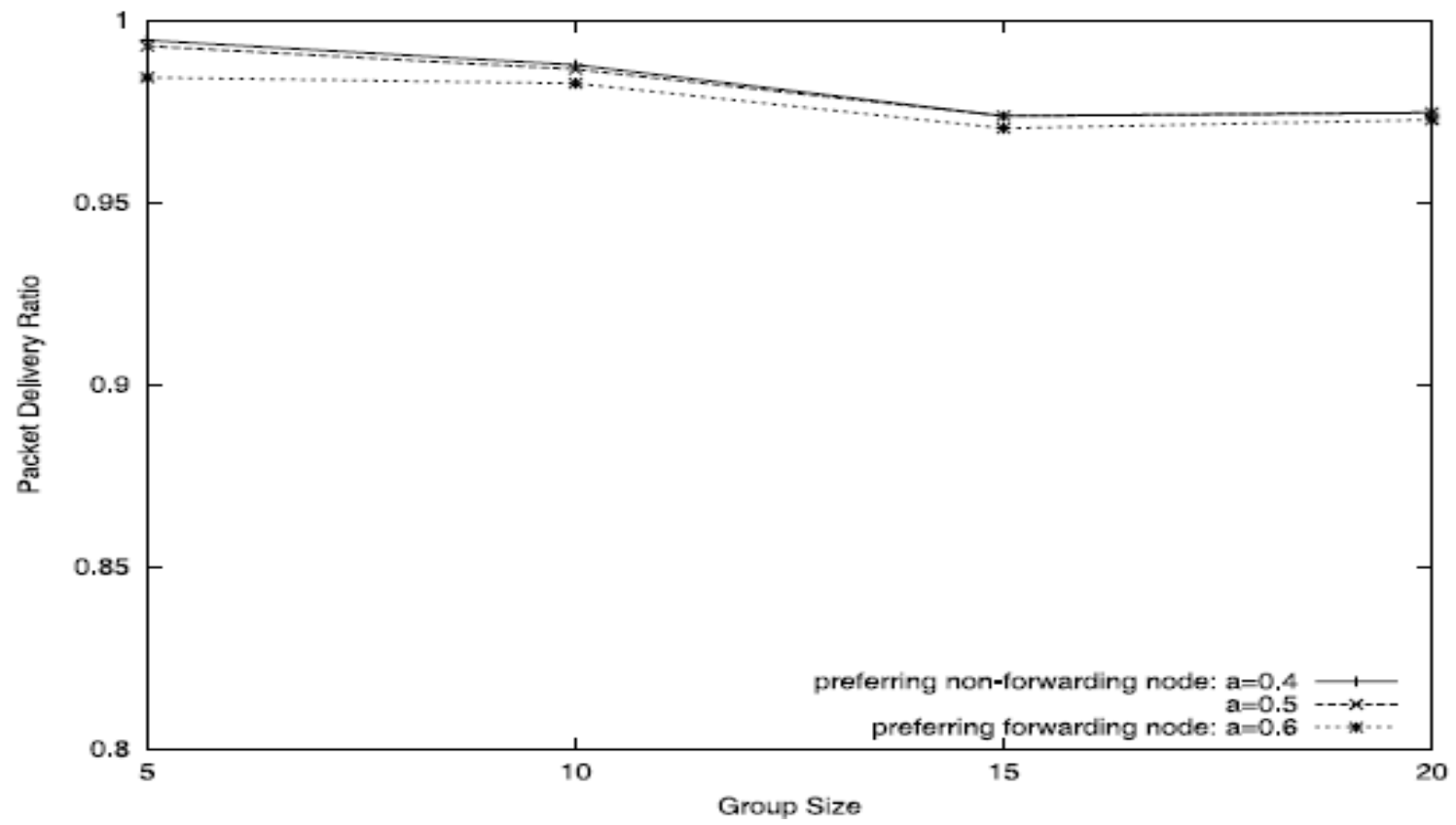

Figure 7. Data delivery ratio with different weight 


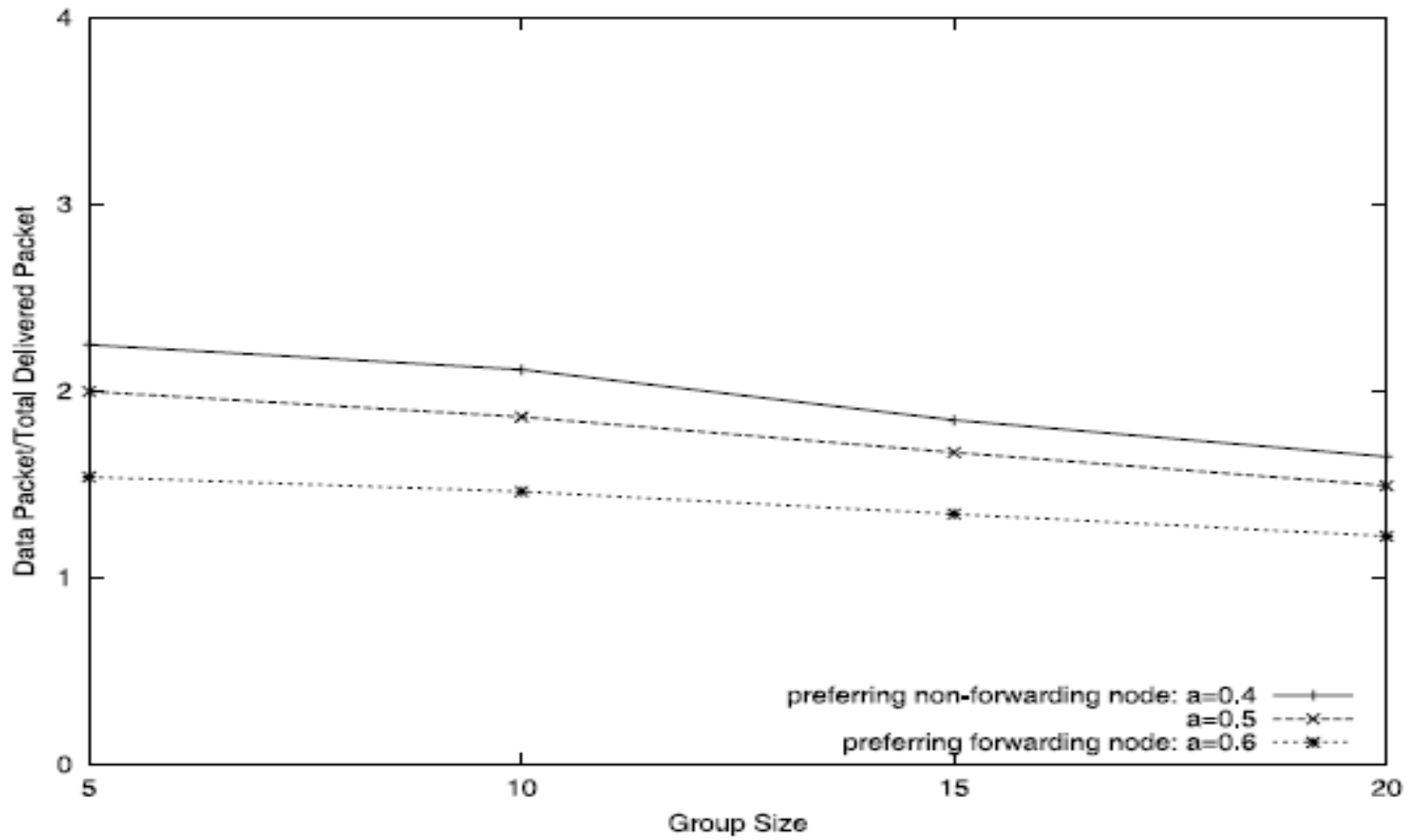

Figure 8. Transmission of Data packets with different weight

\subsection{Comparison Study of Various Parameters in SSMR Protocol}

In this we compared the results of the simulated SSMR protocol with other protocols like ODMRP \&MAODV. If we considered a group has two sources nodes with five receivers then the transmission range is set to 250 meters, we can vary the speed of resilience of protocols against the node mobility. It is clearly shown in the Figure 9, node speed with packet delivery ratio from this we discovered that as the speed of the node increases then performance of the MAODV reduces rapidly. Similarly to the ODMRP performance varies in such a way that SSMR performs the local failure recovery but this will performs the global failure recovery.

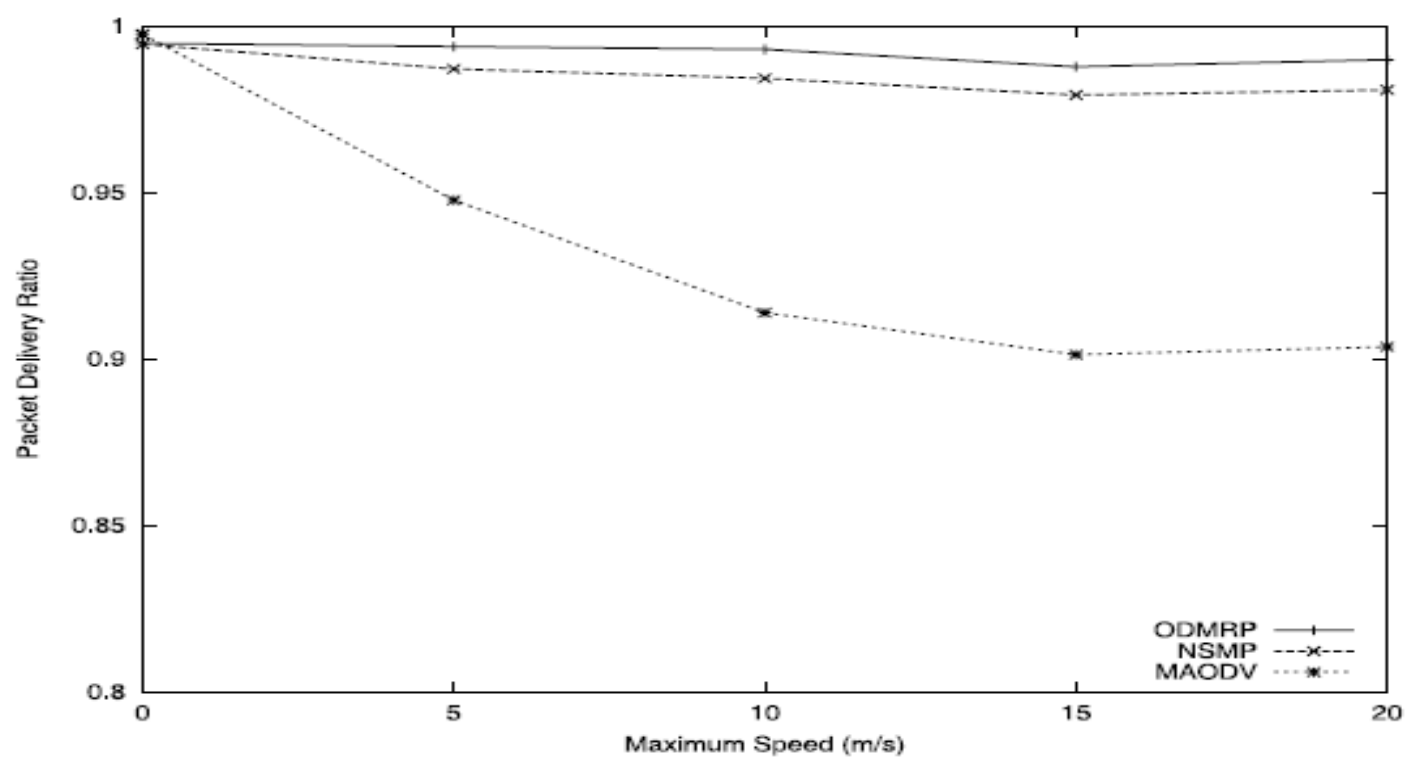

Figure 9. Comparison of mobility change \& data delivery ration 
Variation in terms of data transmission with SSMR protocol with other protocols like ODMRP \& MAODV. This clearly shows in the Figure 10, the MAODV has lower speed of data compared with SSMR protocol and the control overhead of ODMRP is larger than the SSMR overhead. In the simulation duration the transmission range will be static at $250 \mathrm{~m}$ and the maximum speed is set to the $10 \mathrm{~m} / \mathrm{s}$ of the grough which have a 5 receivers with one group source head, so the ODMRP \& SSMR protocol will perform more better than the MAODV in maximum cases. However as the source node increases then performance decreases due to intense traffic. But by the use of SSMR protocol will control the data transmission. As a whole the SSMR will play a best role in the data transmission from source to destination.

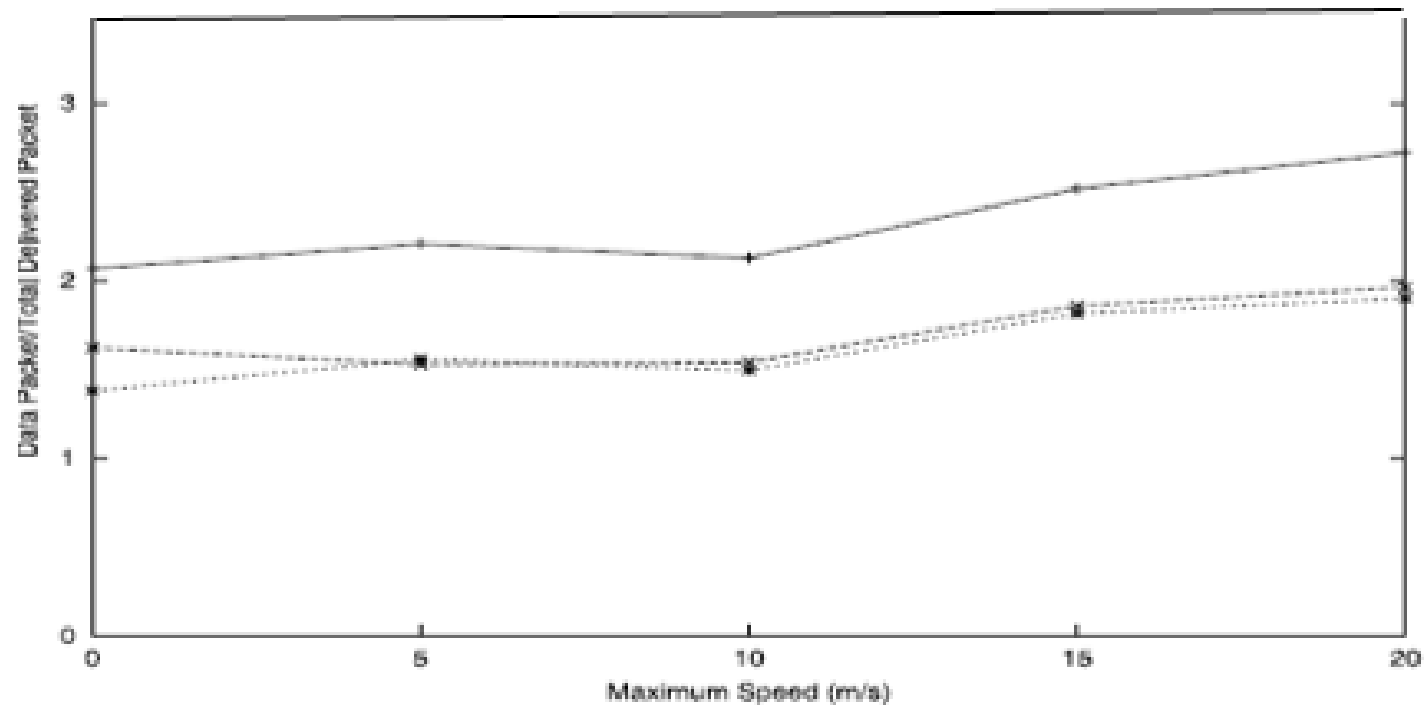

Figure 10. Data transmission comparison with mobility changes with ODMRP, SSMR MAODV

\section{CONCLUSION}

In this paper we propose a protocol for the Adhoc networks which is basis on on demand multicast routing scheme which is called a new protocol as SSMR protocol. This protocol is designed for the efficient data transmission from source to destinations and to controls minimizes the overhead in maintaining the multicast mesh network. The simulation analysis also done using NS-2 simulator. From this analysis we get clear says that SSMR will decreases the overhead and increases the route efficiency from source node to intermediate nodes and destination node. This protocol will increase the mobility of nodes and group size as it will set as mesh structure. And the future works will be done on the energy harvesting and route discovery packets.

\section{REFERENCES}

[1] C. Perkins, P. Bhagwat, Highly dynamic destination- sequenced distance-vector routing (DSDV) for mobile computers, ACM SIGCOMM, October 1994.

[2] Murthy, J.J. Garcia-Luna-Aceves, An efficient routing protocol for wireless networks, ACM Mobile Networks and Applications Journal, Special issue on Routing in Mobile Communication Networks, 1996.

[3] D. Bertsekas, R. Gallager, Data Network, second edition, Prentice-Hall, Englewood Cliffs, NJ, 1992, pp. 404-410.

[4] G. Aggelou, R. Tafazolli, RDMAR: a bandwidth-efficient routing protocol for mobile ad hoc networks, Proceedings of The Second ACM International Workshop on Wireless Mobile Multimedia (WoWMoM), Seattle, WA, August 1999.

[5] C. Perkins, E.M. Royer, S.R. Das, Ad Hoc on Demand Distance Vector (AODV) routing, Internet Draft, IETF, June 1999.

[6] C.K. Toh, Long-lived Ad Hoc Routing based on the Concept of Associativity, Internet draft, IETF, March 1999.

[7] J. Broch, D.B. Johnson, D.A. Maltz, The dynamic source routing in ad hoc wireless networks, in: T. Imielinski, H. Korth (Eds.), Mobile Computing, Kluwer Academic Publishers, Dordrecht, 1996, pp. 153-181 (Chapter 5).

[8] V. Park, S. Corson, Temporally-Ordered Routing Algorithm (TORA), ver. 1, Internet draft, IETF, August 1998.

[9] E. Royer, C.E. Perkins, Multicast operation of the ad-hoc on-demand distance vector routing protocol, MobiCom'99, August 1999.

[10] S. Lee, W. Su, M. Gerla, Ad hoc wireless multicast with mobility prediction, IEEE ICCCN’99, Boston, MA, October 1999. 